\title{
Motivos que levam os voleibolistas a retornarem ao Brasil após a expatriação
}

http://dx.doi.org/10.11606/1807-5509201900010085

\author{
Ivan Wallan TERTULIANO* \\ Vivian de OLIVEIRA** \\ Daniel BARTHOLOMEU**** \\ Luciana Botelho RIBEIRO**** \\ José Maria MONTIEL** \\ Afonso Antonio MACHADO*****
}

${ }^{*}$ Centro Universitário

Adventista de São

Paulo, São Paulo, SP

Brasil.

${ }^{* *}$ Centro Universitário Fundação Instituto de

Ensino para Osasco,

Osasco, SP, Brasil.

${ }^{* * *}$ Centro Universitário Salesiano São Paulo,

Americana, SP, Brasil.

****Universidade

Estadual Paulista Júlio de Mesquita Filho, Rio

Claro, SP, Brasil.

\section{Resumo}

0 objetivo do presente estudo foi analisar os motivos que levam os atletas de Voleibol a retornarem ao seu país de origem, após a expatriação e como os mesmos avaliam o processo de expatriação para sua carreira. Participaram 30 pessoas, sendo 20 atletas (17 homens e 3 mulheres), e 10 ex-atletas ( 2 homens e 8 mulheres), com média de idade de 30,96 anos. 0 instrumento utilizado foi desenvolvido e validado via TRI, utilizando-se do ajuste ao modelo de Rasch. 0 mesmo foi construído em 2 partes, sendo a primeira parte responsável por caracteristicas gerais, contendo questões abertas e fechadas, e a segunda parte responsável por questões de adaptação, contendo apenas questões fechadas com respostas em escala do tipo Likert de 5 pontos. No presente estudo, apenas as questões pertinentes aos objetivos foram analisadas. Para as análises inferenciais, utilizou-se da Anova one-way com medida repetida no último fator, teste $t$ pareado e Correlação de Pearson. Quando foram encontradas diferenças significantes, conduziu-se testes de post hoc. Os resultados demonstraram que os atletas apresentaram como o motivo que mais ocasionou retorno para o Brasil, a saudade da família $(p=0,014)$. Entretanto, mesmo assim, os atletas consideraram proveitosa a expatriação, provavelmente pelo fato de compreenderem o valor de enriquecimento cultural e profissional que o processo lhe trouxe, mesmo não conquistando os títulos e salários esperados. Diante de tais achados, pode-se concluir que o motivo mais importante para o retorno do atleta ao Brasil foi a família, demonstrando a necessidade de treinamento intercultural junto ao atleta e a busca de modelos de expatriação que envolvam a familia no processo, com o intuito de minimizar os danos causados pela saudade da família.

Palavras-Chave: Psicologia do Esporte; Expatriação; Voleibol; Motivação.

\section{Introdução}

Falando-se de esporte, ao se transformar em um produto de massa, assumiu a forma de esporteespetáculo, sendo explorado por parceiros que buscam vantagens econômicas ${ }^{1}$. Dentro dessas transformaçóes, encontra-se a mudança das relaçôes entre clubes e jogadores, facilitando as transferências internacionais, possibilitando novos mercados para os atletas estrangeiros ${ }^{2,3}$. As transferências internacionais passaram a funcionar como um negócio lucrativo, tanto para o clube, quanto para o jogador, proporcionando novas dinâmicas, nesse caso, a expatriação $0^{4,5}$.

BRANDÃO ${ }^{6}$ define expatriado como um funcionário enviado por uma organização para viver e trabalhar em outro país por um período de tempo maior que 1 ano. Nos esportes, expatriação pode ser entendida como a troca de país, por parte de um atleta, para continuar a competir no esporte em que atua, ou até em outro esporte 7 . Expatriação de atletas não 
é algo recente ${ }^{8}$, ocorre desde o início do século XX, mas foi apenas no final do mesmo século, em 1996 que houve aumento dos casos no esporte, muito impulsionado pela mudança das regras e legislação acerca do assunto ${ }^{9}$, em função da lei Bosman, a qual deu direito de trânsito livre para atletas dos países integrantes da União Europeia

Nesse novo cenário, o Brasil é um dos países que mais expatria atletas, principalmente no Futebol ${ }^{4}$. Todavia, existem casos no Voleibol também, podendo citar inúmeros exemplos desses processos, iniciados em 1960, quando o Brasil ganhou reconhecimento mundial, haja vista as conquistas das seleçôes Brasileiras de Voleibol ${ }^{10}$. Falando-se de Futebol e Voleibol, podese observar exemplos dessas informaçóes. Em 2006, o Brasil exportou 348 jogadores de Voleibol para o mundo ${ }^{11}$; no mesmo ano, o Brasil exportou 851 jogadores de Futebol e em 2013 foram 1.530 atletas de Futebol ${ }^{12}$.

Pode-se observar que as expatriaçóes de jogadores estão ligadas ao ganho financeiro envolvendo a negociação, sem ter a devida preocupação com todo o processo de expatriação, citado por alguns autores como fundamental para o sucesso do fenômeno ${ }^{13,14}$. Como os clubes náo se preocupam com o planejamento do processo de expatriação, muitos atletas sofrem com problemas de psicológicos, sentem-se inseguros e acabam retornando para o Brasil antes do prazo devido $^{7,15}$.

Assim, os estudos apontam para o processo de expatriação, no esporte, como um processo artesanal, constituído de tentativa e erro ${ }^{3,16}$, demonstrando a necessidade de estudos que possam contribuir com o planejamento do processo de expatriação. EBBBEN $^{16}$ afirma que elementos culturais, sociais, políticos, religiosos, educacionais, psicológicos, emocionais e afetivos devem ser considerados no planejamento do processo de expatriação.

No âmbito do esporte, esse processo de expatriação foi investigado, em grande parte, no Futebol ${ }^{3,7,9,15,17,18}$, o que abre justificativa para esse estudo, no âmbito do Voleibol, já que até o presente momento, apenas Tertuliano 5 investigou no contexto do Voleibol. Além disso, os estudos apontam para necessidade de estratégias adequadas para o planejamento da expatriação, com o intuito de minimizar possíveis desconfortos psicológicos ${ }^{7}$, contribuindo com uma adaptação adequada ${ }^{5}$. Somado a isso, os estudos tem demonstrado que o retorno do atleta, após a expatriação está muito ligado a não preparação do mesmo e, com isso, ele entra em um estado de "choque cultural"7,17, rejeitando a presente situação e o presente clube, o que pode leva-lo a depressão e/ou desistência do esporte ${ }^{16}$.

Assim, investigar o processo de expatriação esportiva, pode contribuir com a preparação psicológica dos atletas, bem como sua inserção na nova equipe, minimizando os danos pessoais que o processo pode causar no atleta. Como o Voleibol é o segundo esporte mais praticado no Brasil ${ }^{19}$, é relevante a compreensão do processo de expatriação junto aos atletas voleibolistas. Assim, o objetivo do presente trabalho é analisar os motivos que levam os atletas de Voleibol a retornarem ao seu país de origem, após a expatriação e como os mesmos avaliam o processo de expatriaçáo para sua carreira.

\section{Método}

\section{Participantes}

Participaram do estudo atletas e ex-atletas ${ }^{1}$ profissionais de Voleibol. Como forma de identificação do ex-atleta, o questionário apresentava a seguinte questão: "Parou de disputar campeonato?". No presente estudo, apenas atletas profissionais ${ }^{20}$ foram utilizados, ou seja, os atletas que nunca haviam se profissionalizado foram descartados da amostra. Além disso, apenas pessoas com mais de 18 anos participaram do estudo. Por fim, para participar do estudo o atleta deveria ter atuado em clubes de países diferentes do país natal, assim, os atletas que não atuaram em outros países, foram descartados.
Dessa forma, no presente estudo participaram 30 pessoas, sendo 19 homens e 11 mulheres. Desse total, 20 são atletas (17 homens e 3 mulheres), e 10 ex-atletas (2 homens e 8 mulheres), com média de idade de 30,96 anos (DP $=6,73)$. Todos os participantes preencheram um Termo de consentimento livre e esclarecido (TCLE) antes de sua participação na pesquisa.

\section{Instrumento}

Nesse estudo, o instrumento utilizado foi elaborado por Tertuliano 5 . O instrumento foi elaborado em formato de questionário, denominado: 
"Questionário: O processo de Expatriação de Jogadores de Voleibol". Para o processo de elaboração, utilizou-se de três juízes, sendo 2 psicólogos e 1 educador físico, todos com mais de 10 anos de experiência e com expertise na área. O questionário apresentava 2 partes: a primeira parte continha questão em relação as características gerais do participante, de ordem socioeconômica e de dinâmicas da expatriação dos participantes, respeitando-se os princípios éticos de anonimato, pautados na Resoluçáo 466/2012 do Conselho Nacional de Saúde (CNS), sobre pesquisas com seres humanos. Em síntese as questóes dessa parte do instrumento tinham a preocupação de compreender as características socioeconômicas dos participantes, bem como oferecer aos pesquisadores a identificação dos mesmos, enquanto idade, sexo etc.

A segunda parte do instrumento tinha o intuito de compreender a adaptação do participante ao processo de expatriação, tanto em questóes de motivação ao processo de expatriação, a adaptação do atleta ao novo clube e ao novo contexto social, como em relaçáo a percepçáo do atleta sobre todo o processo de expatriação (ver instrumento completo em Tertuliano ${ }^{5}$ ). As questốes foram desenvolvidas com várias categorias de resposta, como as escalas do tipo Likert, servindo para duas funçóes: (1) enfatizar aspectos relevantes das variáveis em questão e (2) em relação à resposta, permitiu ao participante escolher uma categoria intermediária de resposta. Nessa parte do instrumento, as possibilidades de respostas foram: 1 (discordo totalmente), 2 (discordo), 3 (concordo pouco), 4 (concordo) e 5 (concordo totalmente) ou 1 (muito ruim), 2 (ruim), 3 (indeciso), 4 (boa) e 5 (muito boa) para questóes em relação a adaptação ou percepção. Assim, a pontuação para os dois aspectos, percepçáo e adaptação, foi mediada por uso de escala Likert.

No presente estudo, utilizou-se apenas as questóes que atendiam o objetivo do mesmo (QUADRO 1). Dessa forma, questóes que se relacionam a outros objetivos foram descartadas.

QUADRO 1 - Questões utilizadas para o estudo, referente a primeira parte do instrumento desenvolvido por TerTulianO $^{5}$

\begin{tabular}{|l|l|}
\hline \multicolumn{2}{|c|}{ Questóes referentes à primeira expatriaçáo* } \\
\hline 64. & Qual é o último clube que defendeu em outro país? \\
\hline 65. & De qual país é o clube que defendeu? \\
\hline 66. & Sua permanência no clube estrangeiro foi de quanto tempo? \\
\hline 67. & Retornou ao Brasil após jogar pelo clube estrangeiro? ( )Sim ( )Não \\
\hline & Caso a resposta seja SIM \\
\hline 68. & Qual foi o motivo do retorno ao Brasil? \\
\hline 69. & Retornou ao Brasil e continuou a jogar em algum clube? ( )Sim ( )Não \\
\hline & Caso a resposta seja SIM \\
\hline 70. & Em qual clube você jogou ao voltar para o Brasil? \\
\hline 71. & Continua jogando neste clube? ( )Sim ( )Não \\
\hline 72. & Atualmente você mora em qual Cidade/País? \\
\hline 73. & Já defendeu mais de um clube de outro país? ( )Sim ( )Não \\
\hline & \\
\hline 86. & Questóes referentes à segunda expatriaçáo* \\
\hline 87. & Quantas vezes você saiu do Brasil para jogar por clubes de outro país? \\
\hline 88. & Joga atualmente em algum clube em outro país? ( )Sim ( )Não \\
\hline & Caso a resposta seja NÃO \\
\hline 89. & Sua permanência no último clube estrangeiro foi de quanto tempo? \\
\hline 90. & Retornou ao Brasil após jogar pelo último clube estrangeiro? ( )Sim ( )Não \\
\hline & Caso a resposta seja SIM \\
\hline 91. & Qual foi o motivo do retorno ao Brasil? \\
\hline 92. & Retornou ao Brasil e continuou a jogar em algum clube? ( )Sim ( )Não \\
\hline
\end{tabular}

A numeração da variável é referente ao seu número de questão no questionário de TERTULIANO ${ }^{5}$. 
Em relação a segunda parte do instrumento, também utilizou-se algumas questôes, sendo apenas as que atendiam ao objetivo desse estudo. As questóes da segunda parte que foram utilizadas neste trabalho, foram as que, após a análise de TRI (Teoria de resposta ao Item) pelo uso do modelo de Rasch, se encontraram ajustadas ao modelo. Essas análises foram conduzidas pois o instrumento foi desenvolvido e se precisava garantir sua validade psicométrica, ou seja, na construção e validação de instrumentos psicométricos que buscam explicar a probabilidade que uma pessoa tem de responder a um determinado item ${ }^{21}$ é necessário a análise de seus itens. Assim, tal análise teve como objetivo, avaliar a unidimensionalidade do instrumento, ou seja, a análise de componentes principais de resíduos pelo modelo de Rasch. Assim, verificou-se os itens que se ajustam ao modelo, para depois avaliar a dificuldade e habilidade de itens e pessoas, respectivamente e, com isso, utilizar apenas as questóes ajustadas ao modelo para a fase de análises inferenciais. Após todas as análises de ajuste dos itens ao modelo de Rasch, restaram as questôes ajustadas (QUADRO 2).
A numeração da variável é referente ao seu número de questão no questionário de TeRTULIANO ${ }^{5}$.

QUADRO 2 - Questões utilizadas para o estudo, após análise de ajuste dos itens ao modelo Rasch

\begin{tabular}{|l|}
\hline Questóes utilizadas para o presente artigo, após análise de ajuste ao modelo de Rasch \\
\hline 1. A experiência da primeira vez de mudança de clube/país foi: \\
\hline 2. A experiência da última vez de mudança de clube/país foi: \\
\hline 1. Foi muito proveitoso o processo de mudança de clube. \\
\hline 4. Aconselho a todos os atletas passarem por esse processo de mudança de clube. \\
\hline 9. Conquistei os títulos que esperava no novo clube \\
\hline 11. Conquistei o espaço que esperava no novo clube \\
\hline 12. A torcida do novo clube me adorava \\
\hline 13. A equipe do novo clube me adorava. \\
\hline 14. Fui feliz em meu novo clube. \\
\hline 5. Aconselho a todos passarem por esse processo de mudança de país. \\
\hline 7. Considero minha experiência importante para ajudar os futuros atletas no processo de mudança de país. \\
\hline 8. Tendo em vista meus objetivos de sair do país, eles foram alcançados. \\
\hline 16. Conquistei o respeito que esperava no novo país. \\
\hline 21. Fiquei com medo quando tive que retornar. \\
\hline 24. Fiquei com raiva quando voltei. \\
\hline
\end{tabular}

\section{Procedimentos}

A pesquisa respeitou os princípios legais de uma pesquisa que envolve coleta de dados com seres humanos. A pesquisa foi aprovada pelo Comitê de Ética e Pesquisa (CEP) do Instituto de Biociências de Rio Claro/Universidade Estadual Paulista (parecer número: 1.537.814). Após aprovação, iniciou-se a mesma, convidando os participantes do estudo via contatos pela internet $\left(\right.$ Facebook $^{\circledR}$ e E-mail) ${ }^{22}$. Neste convite, o estudo era explicado aos possíveis participantes, enquanto objetivos e regras, além de orientar ao convidado que o mesmo poderia desistir do estudo se desejasse, em qualquer momento da pesquisa.

Após aceite do convite, o participante recebeu, por E-mail, o TCLE, o qual foi devolvido preenchido e assinado, via e-mail. Para os participantes que devolveram o TCLE preenchido e assinado, foi aplicado o instrumento de pesquisa, o qual poderia ser conduzido de forma eletrônica, de acordo com o CEP que aprovou o mesmo. Enquanto aplicação o instrumento foi conduzido aos participantes de forma eletrônica, com o uso do Google Formulários ${ }^{\oplus 1}$.

Os participantes receberam o link para acessarem ao questionário e responder. Como forma de garantir que apenas os participantes com TCLE, devidamente preenchido e assinado, pudessem fazer parte da amostra, o instrumento, no Google Formulários ${ }^{\bullet}$, continha o campo nome como obrigatório, o qual era comparado com o nome do TCLE. Caso o nome do participante que aparecia no Google Formulários ${ }^{\oplus}$ fosse diferente de algum dos TCLE ou náo contivesse nos documentos de TCLE, esse foi descartado. Após 
o término da aplicação do instrumento, em todos os participantes, os dados foram importados do Google Formulários ${ }^{\oplus}$ para o Office, em formato de planilha Microsoft Excel 2016.

\section{Procedimentos de análise}

O presente estudo trata-se de um estudo experimental. Sendo assim, esse estudo apresenta análises descritivas e inferenciais, pois foi assumida a abordagem quanti-qualitativa como forma de compreensão dos dados e, com isso, conseguir responder aos objetivos do estudo. Em relação as análises, as mesmas foram conduzidas apenas nas questóes citadas nos quadros acima.

A primeira parte do instrumento era composta por questóes abertas e questóes fechadas. Frente às questóes abertas, elas foram consideradas, para medida, como variáveis nominais. As variáveis nominais (medidas nominais) são conhecidas como dados categóricos ou qualitativos. Desta forma não existe relação com escala de ordem (maior ou menor). Elas representam apenas a diferença entre uma variável e outra ${ }^{23,24}$. Tais variáveis, foram analisadas por meio do software IBM SPSS Statistics, versão 20.

Para análise da primeira parte do instrumento, utilizou-se de estatística descritiva, ou seja, houve a preocupação em descrever os dados, sintetizando uma série de valores de mesma natureza, permitindo uma visão global das variaçôes desses valores ${ }^{25}$. Após a estatística descritiva, aplicou-se estatística inferencial em algumas variáveis (as variáveis que respondiam ao objetivo do estudo). Para testar a normalidade foi utilizado do Teste Kolmogorov-Smirnov (K-S) e para testar a homogeneidade de variância o teste de Levene. Em relação a normalidade, o teste K-S demonstrou $\mathrm{p}>0,05$, ou seja, existe normalidade nas variáveis investigadas. Frente a homogeneidade de variância, o teste de Levene demonstrou $p>0,05$, o que demonstra que a variância de uma variável é estável em todos os níveis da outra variável, em outras palavras, existe homogeneidade de variância ${ }^{26}$. Assim, assumiu-se normalidade na primeira parte do instrumento e utilizou-se o valor Alfa de 0,05.

Em relação a segunda parte do instrumento, após todas análises de ajuste ao modelo Rasch, conduziu-se análises apenas nas questóes ajustadas ao modelo de Rasch e que respondiam ao objetivo do presente estudo, conforme citado anteriormente ${ }^{27}$. De acordo com a teoria do limite central, quanto maior o tamanho da amostra, a distribuição das médias estará mais próxima de uma distribuição normal. Green, SAlkind e Akey ${ }^{28}$ sugerem que em um grupo com mais de 30 participantes é possível assumir normalidade e homogeneidade de variância sem o uso de testes. Dessa forma, assumiuse normalidade, utilizando o valor Alfa de 0,05 para diferenças significativas.

Assumindo normalidade nas duas partes do instrumento, para as análises, utilizou-se da Anova one-way com medida repetida no último fator, teste $t$ pareado e Correlação de Pearson. Quando foram encontradas diferenças significantes, conduziu-se testes de post hoc. Para controle do erro tipo 1, foi utilizado o procedimento sequencial Holm de Bonferroni ${ }^{28}$.

\section{Resultados}

Para o primeiro objetivo do estudo, que é analisar os motivos que levam os atletas de Voleibol a retornarem ao seu país de origem, utilizou-se apenas as questóes da primeira parte do instrumento. Em relaçáo aos resultados, os mesmos foram analisados em 2 momentos, já que a maior parte dos atletas participaram da expatriação mais de uma vez, buscouse compreender o retorno ao Brasil em diferentes momentos. Assim, os resultados demonstraram que dos 30 participantes, na primeira expatriação, 19 participantes retornaram ao Brasil após jogar pelo clube estrangeiro e 11 continuaram fora do Brasil.

Desses 19 atletas que retornaram ao Brasil, 7 participantes retornaram por saudade da família,
6 retornaram por término do contrato e os demais por outros motivos. Em análise inferencial, o teste Anova one-way com medidas repetidas no último fator identificou diferença significante $(p=0,036)$. No que concerne à localização da diferença, o Teste de post hoc de Bonferroni apontou a diferença entre saudade da família e aposentadoria, lesão e término da bolsa de estudo $(\mathrm{p}=0,014)$. Tais resultados indicam que a variável saudade da família apresentou valores significantes para o retorno ao Brasil, seguido do término do contrato, corroborando a análise descritiva. Essas informaçóes sugerem a necessidade de preparação do atleta para a expatriaçáo. 
Em relação à permanência no clube estrangeiro, os participantes ficaram no outro país por um período de 2 meses a 72 meses, tendo 18 participantes ficado mais de 1 ano no novo país. Dos 19 participantes que retornaram ao Brasil, 8 continuaram a jogar Voleibol após o retorno, tendo os outros 11 atletas se aposentado (1 atleta) ou se tornado desempregado (10 atletas). Desses 19 atletas que retornaram ao Brasil, 15 saíram outra vez, para uma equipe internacional, sendo que 12 atuavam em equipes no Brasil e 3 estavam desempregados, mas moravam no Brasil.

Desses 15 expatriados que saíram outra vez, 9 retornaram ao Brasil e 6 continuaram a atuar no exterior. Dos 9 que retornaram, 7 ficaram menos de 9 meses no novo país. Em relaçáo aos motivos do retorno, os resultados demonstram que a maior parte dos participantes retornaram por saudade da família (4 atletas). Em análise inferencial, o teste Anova one-way com medidas repetidas no último fator não apresentou diferenças significantes entre os motivos de retorno $(\mathrm{p}=0,288)$, porém, frente à média, a saudade da família foi o fator mais relevante.

Quando se faz a comparação entre os motivos que levaram os participantes a retornarem ao Brasil, após a expatriaçáo, tanto na primeira vez, quanto na segunda vez, verifica-se que a saudade da família é o fator determinante para o retorno, conforme TABELA 1, o que demonstra o papel que os familiares exercem sobre a permanência do participante em outro país. Entretanto, o Teste Anova one-way com medidas repetidas no último fator não demonstrou diferença significativa entre os motivos de retorno na primeira e na segunda expatriação $(\mathrm{p}=0,681)$.

Em relação às médias, os valores das duas expatriaçóes ficaram entre 1 e 2 (1,777 para primeira expatriação e 1,888 para segunda expatriação), sugerindo que os motivos mais relevantes para o retorno são, em primeiro lugar a saudade da família e, em segundo lugar, o término do contrato, nas duas expatriaçóes, corroborando a análise descritiva e as análises para cada momento.
*Valores apresentados em frequência relativa do número de participantes.
Valores apresentados em frequência relativa do número de participantes.

TABELA 1 - Comparação dos motivos de retorno ao Brasil na primeira expatriação e na segunda expatriação

\begin{tabular}{lcc}
\hline Motivos de Retorno ao Brasil & $\begin{array}{c}\mathbf{1}^{\mathbf{a}} \text { expatriaçáo } \\
(\mathbf{n = 1 9 )}\end{array}$ & $\begin{array}{c}\mathbf{2}^{\mathbf{a}} \text { expatriaçáo } \\
(\mathbf{n}=\mathbf{9})\end{array}$ \\
\hline 1. Saudade da Família & $37,50 \%$ & $44,50 \%$ \\
2. Término de contrato & $31,25 \%$ & $22,30 \%$ \\
3. Proposta melhor no Brasil & $12,50 \%$ & ---- \\
4. Aposentadoria & $6,25 \%$ & $33,20 \%$ \\
5. Lesão & $6,25 \%$ & $-\cdots--$ \\
6. Término da Bolsa de Estudo & $6,25 \%$ & ---- \\
Média & 1,7778 & 1,8889 \\
DP & 0,97183 & 1,26930 \\
\hline
\end{tabular}

Em relação ao tempo de permanência na expatriação, os resultados demonstraram que 7 dos participantes, na segunda expatriação, retornaram ao
Brasil antes de 1 ano de expatriação, indicando que os participantes ficaram mais tempo fora do Brasil na primeira expatriação (TABELA 2).

TABELA 2 - Tempo de permanência na primeira e na segunda expatriação

\begin{tabular}{lcc}
\hline Tempo de permanência & $\begin{array}{c}\mathbf{1}^{\mathbf{a}} \text { expatriaçáo } \\
(\mathbf{n}=\mathbf{1 9 )}\end{array}$ & $\begin{array}{c}\mathbf{2}^{\mathbf{a}} \text { expatriaçáo } \\
(\mathbf{n}=\mathbf{0 9})\end{array}$ \\
\hline 2 a 12 meses & $40 \%$ & $77,80 \%$ \\
13 a 24 meses & $43,30 \%$ & $11,10 \%$ \\
25 a 72 meses & $16,70 \%$ & $11,10 \%$ \\
Média & 20,11 & 11,33 \\
DP & 16,351 & 11,079 \\
\hline
\end{tabular}


Em relação a segunda parte do instrumento, considerando quanto os participantes perceberam de sua adaptação ao processo de expatriação, utilizouse dos itens $1,2,1,4,9,11,12,13,14,5,7,8$ e 16 (TABELA 3). Em uma análise descritiva, parece que os participantes, mesmo náo conquistando os títulos almejados, consideraram adequada a sua expatriação, sendo que a primeira expatriação foi mais proveitosa, enquanto experiência do que a segunda, provavelmente pelo fato de a primeira ser novidade ao participante. Em uma análise inferencial, o teste Anova one-way com medidas repetidas no último fator apresentou diferença significante entre os itens $(\mathrm{p}=0,022)$. Sobre as diferenças, o teste post hoc de Bonferroni apontou para a diferença entre a conquista de títulos (item 9) e os demais itens $(\mathrm{p}<0,050)$, com exceção dos itens 2 e 11 , que não apresentaram diferença significante em relação ao item 9. Essas informaçóes confirmam a análise descritiva, ou seja, os atletas consideraram boa a sua adaptação no processo de expatriação, sendo a primeira mais positiva do que a segunda.

Além disso, a falta das conquistas que esperavam e o espaço no clube que alguns não conseguiram, não diminuiu, para os participantes, a qualidade do processo de expatriação já que se demonstram felizes com a expatriação e aconselham a expatriação para os demais atletas.

TABELA 3 - Itens relacionados à percepção do atleta sobre sua expatriação $(\mathrm{n}=30)$

\begin{tabular}{lcc}
\hline \multicolumn{1}{c}{ Variável** } & Média & DP \\
\hline 1. A experiência da primeira vez de mudança de clube/país foi: & 4,60 & 0,498 \\
2. A experiência da última vez de mudança de clube/país foi: & 4,33 & 0,959 \\
1. Foi muito proveitoso o processo de mudança de clube. & 4,57 & 0,935 \\
4. Aconselho a todos os atletas passarem por esse processo de mudança de clube. & 4,40 & 0,855 \\
9. Conquistei os títulos que esperava no novo clube & 3,17 & 1,663 \\
11. Conquistei o espaço que esperava no novo clube & 4,13 & 1,408 \\
12. A torcida do novo clube me adorava & 4,27 & 1,048 \\
13. A equipe do novo clube me adorava. & 4,43 & 0,774 \\
14. Fui feliz em meu novo clube. & 4,33 & 0,994 \\
5. Aconselho a todos passarem por esse processo de mudança de país. & 4,57 & 0,774 \\
7. Considero minha experiência importante para ajudar os futuros atletas no processo de & 4,57 & 0,817 \\
mudança de país. & 4,33 & 1,061 \\
8. Tendo em vista meus objetivos de sair do país, eles foram alcançados. & 4,17 & 1,234 \\
16. Conquistei o respeito que esperava no novo país. & & \\
\hline
\end{tabular}

** a numeração da variável é referente ao seu número de questão no questionário.
Por fim, sobre o retorno dos atletas, pode-se observar nas médias dos itens 21 e 24 que os atletas tiveram um pouco de medo, mas não demonstraram raiva em seu retorno. Esses resultados sugerem que a volta foi um pouco incerta, possivelmente pelo fato de alguns terem retornado desempregados informação apresentada na primeira parte do instrumento - mas sem raiva de terem que voltar, possivelmente pelo fato da saudade da família informação que foi apresentada como maior causa do retorno dos atletas ao Brasil.

A análise descritiva foi comprovada pela análise inferencial, haja vista o teste $t$ pareado ter apresentado diferença significante entre os itens $(\mathrm{p}=0,002)$, ou seja, o medo foi maior que a raiva. Em relação à correlação entre os itens, o teste de correlação de Pearson apresentou correlação fraca $(r=0,361$, $\mathrm{p}=0,050$ ), ou seja, não existe influência de um item sobre o resultado do outro, para essa amostra. Frente à correlaçáo do motivo de retorno (itens 21 e 24), o teste de correlação de Pearson apresentou correlação fraca $(r<0,400)$, não corroborando a análise descritiva.

Em síntese, 19 participantes que foram a primeira vez retornaram ao Brasil após a expatriação e 7 participantes que foram a segunda vez retornaram ao Brasil após a expatriação. Em ambos os momentos, o maior motivo de retorno dos atletas foi a saudade da família $(\mathrm{p}>0,05)$, sugerindo que a maior parte dos atletas náo perdem o laço com seu país de origem, nem com a família, o que é corroborado pela literatura'. 


\section{Discussão}

De acordo com os objetivos do presente manuscrito que eram analisar os motivos que levam os atletas de Voleibol a retornarem ao seu país de origem, após a expatriação e como os mesmos avaliam o processo de expatriaçáo para sua carreira, discute-se os resultados encontrados, demonstraram que a saudade da família foi o motivo mais apontado pelos participantes para o seu retorno, seguido do término de contrato.

Além disso, na primeira expatriação os atletas ficaram mais tempo no outro país, em média 20,11 meses do que na segunda expatriação (11,33 meses). De acordo com BrANDÁo et al. ${ }^{7}$, a expatriaçáo pode gerar distanciamento da família, levando o atleta a sentir falta de casa e, com isso, o expatriado pode sentir-se emocionalmente desconfortável, exausto mentalmente, ficar ansioso, triste etc. Somado a isso, muitas vezes, os atletas passam pelo processo de expatriação sozinhos, distantes da família e com comunicação com os familiares de forma virtual ou por cartas ${ }^{17}$, o que pode gerar problemas de adaptaçáo do atleta ao processo de expatriação.

Frente aos resultados, os atletas demonstraram ajustamento intercultural, ou seja, habilidade em se adaptar ao novo ambiente cultural de modo eficiente e suficientemente confortável ${ }^{29}$, já que os resultados demonstraram que os atletas consideraram a expatriação satisfatória e benéfica para o seu crescimento profissional. Todavia, essa adaptação não diminuiu a vontade dos atletas retornarem ao país de origem. Essa informação foi confirmada pelos resultados que demonstraram a saudade da família como fator determinante para o retorno do atleta. Assim, os resultados desse estudo sugerem que os atletas sentiram saudade da família e que esse sentimento os levou a retornar ao Brasil, mesmo considerando a expatriação satisfatória e benéfica.

De acordo com BlAcK ${ }^{30}$, o expatriado passa por adaptação geral, adaptação ao trabalho e adaptação quanto à interação. A adaptação geral diz respeito à adaptação frente a temperatura, alimentação, transporte, compras, diversão e vida em geral na cultura de destino. A adaptação ao trabalho refere-se à adaptação enquanto padrões de trabalho, liderança e relacionamentos profissionais com companheiros no exterior. A adaptação quanto à interação, referese ao conforto psicológico fora do trabalho, ou seja, às relaçóes de amizade e convívio ${ }^{31}$. Tratando-se do presente estudo, observa-se, pautado nos resultados, que os atletas do presente estudo não conseguiram se adaptar ao novo trabalho, pois buscaram retornar ao Brasil, corroborando com os dados da literatura ${ }^{30,31}$.

De acordo com Holopainen e BJÖRKMAN ${ }^{32}$, para que o expatriado tenha sucesso deve ter habilidade para comunicação, independente de dominar o idioma local. Além disso, o expatriado que apresentar experiência de expatriação tende a ter mais sucesso no processo. E mais, os expatriados devem passar por treinamentos acerca da cultura do novo país, para ajudá-los na percepção dessa mudança. Neste estudo, dados os resultados positivos do processo de expatriação, parece que os atletas não tiveram problemas com o idioma local, pois os atletas consideram positiva a expatriação. Porém, em um olhar mais cuidadoso, pode-se especular que o retorno em menos de 1 ano, na segunda expatriação, pode ter relaçáo com a idade do atleta e com contratos mais curtos, já que os atletas que saíram pela segunda vez eram mais velhos e já conheciam o processo de expatriação, ou ainda ter relação com a falta de adaptação ao novo país, corroborando com o supracitado, em que o sucesso deve-se a uma adequada adaptação ao novo contexto (ambiente, idioma etc.).

De acordo com Machado e Hernandes ${ }^{33}$, o expatriado pode se deparar com situações de confronto de sua cultura com outras culturas, ocasionando no expatriado um conflito psicológico, decorrente da dificuldade em reconhecer a outra cultura. Nessa relação com a nova cultura, o expatriado constrói a visão de si mesmo, contribuindo com a construção da identidade e da compreensão da diferenciação com o outro. Diante disso, a inserção do expatriado na sociedade, enquanto convívio social, acontece pelas identificações e pelas diferenciações, estabelecendo fronteiras psicológicas entre os limites pessoais e dos nativos. No presente estudo não foi possível observar ou avaliar tais informaçóes, demonstrando limitações do estudo.

Retomando os resultados, os dados sugerem que os atletas não levaram seus familiares na expatriação. Com isso, era esperado que os mesmos tivessem problemas de adaptação frente à expatriação, o que ocorreu. Os resultados deste estudo apontaram que os atletas retornaram motivados pela saudade da família, corroborando a literatura ${ }^{7,9,16,17,31,34-36}$. Assim, observa-se que a falta de adaptação fez com que os atletas buscassem o retorno para poderem sentir-se seguros junto a família.

Tais resultados demonstram que os familiares junto ao atleta podem auxiliar no processo de 
adaptação à expatriação, conforme a literatura demonstra ${ }^{3,7,9,17}$. Uma possível explicação para o retorno que está relacionada à saudade da família foi a distância que o processo de expatriação gerou entre o expatriado e a família e, com isso, o expatriado buscou o retorno como instrumento de redução da saudade que sentia da família, já que a mesma encontrava-se distante dele. Corroborando com o discutido até agora, em relação a família, Pereira, Pimentel e Kato ${ }^{35}$, apontam que o sucesso da expatriação tem relação direta com o papel da família no processo de adaptação à expatriação. Somado a isso, os autores afirmam que o contato que se espera que o expatriado faça com a nova cultura não é apenas um contato superficial e sem inserção na nova cultura, mas uma imersão ao novo ambiente. Assim, espera-se que o expatriado seja um agente ativo. Entretanto para isso, ele necessita de recursos para atuação, os quais são originários de sua cultura e do suporte que a família oferece ao mesmo.

No presente estudo, como a família não se fez presente, pode-se interpretar que os atletas náo atingiram o sucesso no processo de expatriação, já que muitos retornaram antes mesmo do término do contrato, por falta da família junto a ele nessa nova cultura. Dessa forma, compreendese que a construção do espaço de convivência do expatriado com a nova cultura é fortalecida pela presença constante e marcante dos elementos de sua cultura de origem, o que neste caso, apresentase pela família, que se faz necessária ${ }^{35}$. Alguns estudos sobre expatriação reforçam o argumento sobre a importância da família ${ }^{30,35,37}$, corroborando os achados do presente estudo. Tais estudos demonstram que a aceitação de tarefas em outras localidades, sem a transferência dos familiares reduz a quantidade de adeptos ao processo de expatriação.

A expatriação sem os familiares pode ocasionar o choque cultural de forma mais forte que a expatriação acompanhada da família ${ }^{30,37}$. Além disso, esses estudos demonstram que o convívio com os nativos é facilitado quando existe o apoio da família e que a dedicação no trabalho é maior, assim com o sucesso na carreira.

No presente estudo a falta de dedicaçáo ao trabalho não ocorreu, todavia, poderia ser melhor, se a família estivesse com o expatriado, dando suporte emocional e acompanhando-o no processo de convívio com o novo país ${ }^{38}$. Dentro dessa percepção, enviar a família junto ao expatriado passa a ter fundamental papel, não só na adaptação do mesmo, mas no sucesso da tarefa à qual o expatriado foi designado ${ }^{35}$. De acordo com Sousa ${ }^{36}$, a família é uma forma de os expatriados obterem estabilidade emocional e suporte diante das novas situaçôes que possam ocorrer no processo de expatriação, podendo reduzir os problemas de adaptação, como por exemplo ansiedade, medo, solidão etc.

Nessa perspectiva de apoio familiar, existe a vontade por parte da família expatriada em descobrir novas culturas, novos costumes e novos hábitos, o que contribui com a adaptação do expatriado frente à sociabilizaçáo e ao ajustamento intercultural ${ }^{36}$. Todavia, essa vontade é comum no período de "lua de mel" da família e do próprio expatriado. O problema da família junto ao expatriado é que os impactos do choque cultural são transferidos para a família do expatriado, o que pode gerar, nesse caso, um choque cultural na família. Assim, devese pensar com cautela esse processo de expatriação da família, pois nesse caso, o atleta ficará horas por dia sem contato com a cultura local, já que estará em treinamento no clube, o que não ocorrerá com a família. Em outras palavras, a família deve ser inserida no processo de expatriaçáo, mas o treinamento da mesma se faz necessário, para que todos, atleta e família, possam adaptar-se de forma adequada ao processo de expatriação. Nesse sentido, alguns trabalhos, com o intuito de minimizar os impactos e facilitar o ajustamento cultural do expatriado e de sua família, são realizados pelas empresas ${ }^{35,39}$, mas no ambiente esportivo isso não ocorre. Esses programas são fundamentados em duas perspectivas:

a) Fatores relacionados ao trabalho, de forma que se inclua o expatriado no novo trabalho, ambientando-o com a nova função, grau de envolvimento, limitações técnicas e de recursos, legislação local, objetivos da expatriação etc.;

b) Fatores relacionados à cultura organizacional e fora do trabalho, de forma a dar suporte ao expatriado e a seus familiares, como moradia, escola, instruçóes sobre os serviços locais (supermercado, cinema, hospitais etc.), instruções que auxiliam na redução da distância entre as culturas etc.

Somado a tudo isso, tomando-se os resultados do presente estudo como base, o papel da família é de suma importância para o sucesso e permanência do expatriado no novo país ou até mesmo na nova cidade, quando se trata de expatriação doméstica ${ }^{18}$. 
Assim, Pereira, Pimentel e Kato ${ }^{35}$ sugerem que o processo de expatriação deve ser acompanhado de um treinamento para facilitação do ajustamento intercultural, o que não ocorre no ambiente esportivo. Os autores sugerem que o processo de expatriação deve ocorrer, respeitando-se alguns critérios para o seu sucesso:

a) inclusão, na seleção de candidatos à expatriação, do perfil cultural da família do candidato;

b) ter preferência por candidatos em que a família já teve contato com outra cultura;

c) criação de programas de pré-expatriação com a inclusão de treinamento de comunicação da língua do país hospedeiro;

d) continuidade do programa ao chegar no país de destino.

Os resultados desse estudo, bem como os de Pereira, Pimentel e Kato ${ }^{35}$ e Machado $^{3}$ demonstraram que os clubes não apresentam estratégias ou processos que valorizem a experiência da expatriação. Além disso, demonstraram que os motivos de retorno dos atletas estão relacionados à vontade de estarem próximos aos familiares e amigos, possivelmente por quererem retornar a cultura de origem e sentirem a ausência de seus familiares. Os resultados dos três estudos reforçam a ideia de Rial ${ }^{9}$ de que o atleta, mesmo demonstrando desempenho e sucesso em outro país se sente um estrangeiro, não assumindo, completamente, a cultura do país de destino, podendo gerar a vontade de voltar ao seu país de origem. Tais ocorridos poderiam ser minimizados se os clubes tivessem estratégias de preparação e acolhimento do atleta expatriado, bem como de sua família, como já discutido acima.

Todavia, a expatriação é um fenômeno irreversível na vida do atleta do século XXI. De acordo com PisANi $^{18}$ e Rubio ${ }^{40}$, em função da globalização, os atletas são vistos como mercadorias, muitas vezem em prol do esporte espetáculo. Dessa maneira, o século XXI é acompanhado pela agressividade dos empresários e clubes, tornando o atleta como mera mercadoria e moeda de troca ${ }^{18}$. Em meio à globalização, existe a concorrência entre os atletas, ou seja, existem muitos atletas e poucas oportunidades ${ }^{8}$, aumentando as exigências do mercado esportivo.

De acordo com Rubio ${ }^{40}$, os atletas buscam responder às exigências dos últimos anos $\mathrm{e}$ os melhores passam a ser transformados em mercadorias, vendidas e negociadas pelo mundo. Assim, o esporte competitivo é um tipo de prática que pode se relacionar ao esporte espetáculo, exigindo do praticante um alto grau de dedicação e rendimento ${ }^{41}$, expondo-o, muitas das vezes, ao processo de expatriação como único recurso para a prática do esporte. Olhando-se para os resultados do presente estudo, acerca dessa discussão, observase que o retorno dos atletas pode, também, estar relacionado a essa busca exagerada de rendimento financeiro e, com isso, a comercialização dos atletas sem a mínima preparação ou adaptação do mesmo para que consiga atender as exigências competitivas. Em outras palavras, como os clubes querem ganhar dinheiro com o rendimento atlético do atleta, ele não se preocupa com a preparaçáo e adaptação do mesmo frente a nova cultura e a ausência da família. Porém o mesmo não se dá conta de que essa adaptação é essencial para o sucesso do atleta ${ }^{7}$.

Outro resultado relevante nesse estudo é o fato de os atletas relatarem que o retorno ao Brasil, também está relacionado ao término do contrato junto ao clube internacional. O processo de globalizaçáo tem facilitado as transferências internacionais de atletas, ou seja, os clubes funcionam como verdadeiras empresas que consolidam o comércio internacional de atletas ${ }^{15}$. Essa facilitação levou os clubes a optarem por contratos mais curtos de trabalho, haja vista a possibilidade de não rendimento por parte do atleta. Tal fato pode ocasionar, para o clube, um elevado custo por um "produto" que não estaria em quadra, atuando pela equipe ${ }^{3,4}$.

Retornando aos resultados do estudo, os participantes apresentaram raiva com valores baixos, mas o medo estava inerente ao retorno, possivelmente por estarem longe do Brasil e não saberem ao certo o que fariam ao retornar. Sobre a raiva, a mesma pode ter sido menor por conta da saudade da família, ou seja, por sentirem saudade da família, o sentimento de raiva foi amenizado. Diante dos resultados, o retorno dos atletas foi acompanhado de um componente medo moderado. $\mathrm{O}$ medo está diretamente relacionado à incerteza e é considerado um mecanismo de defesa do ser humano ${ }^{42}$.

Nesse estudo, o medo pode ter relação com a proteção familiar, ou seja, o medo foi gerado pela incerteza de saber se poderia continuar a contribuir, financeiramente, com a família, dando a ela a proteção 
necessária para uma qualidade de vida adequada. Os resultados sugerem que a incerteza do que fazer após a volta levou-os a apresentarem o componente medo, mesmo que em valores baixos. Dessa maneira, os resultados deste estudo, enquanto aspectos emocionais, corroboram a literatura, demonstrando fusão entre felicidade e medo frente a situaçôes novas ${ }^{42-45}$.

Frente a percepçáo dos atletas, os mesmos perceberam como positivo todo o processo e recomendam que outros atletas também façam isso, pois julgam importante o processo de expatriação para a carreira, mesmo não tendo conquistado os títulos almejados e terem voltado por não se adaptarem a distância da família. Além disso, os participantes consideraram a primeira expatriação mais importante para a carreira. Esses resultados encontram-se em consonância com os resultados de CarvalHo ${ }^{46}$, que demonstram que os expatriados, mesmo retornando ao seu país de origem, consideram a realização da expatriação como positiva para suas carreiras. Dessa forma, os expatriados valorizam outros critérios de sucesso na carreira que vão além dos salários, mas que se relacionam com o desenvolvimento de novas competências. Assim, as perspectivas de um expatriado estão relacionadas com os valores, aspiraçóes e expectativas dos atletas e não apenas com a progressão de carreira ${ }^{47}$, enquanto salário.

Além disso, $\mathrm{KANTER}^{48}$, em seu trabalho, apontou que os expatriados consideraram que existiu progressão em suas carreiras pelo fato de lhes serem atribuídos novos trabalhos, esses sendo mais exigentes, desafiantes e levando-os a novos conhecimentos e oportunidades de aplicá-los. Essas perspectivas corroboram os resultados do presente estudo e entram em consonância com o preconizado neste estudo. Assim, os atletas perceberam, na expatriação, uma oportunidade de aquisição de novas competências e conhecimentos, os quais eles julgaram importantes e relevantes, dissociando-os dos ganhos salariais ou de títulos, mesmo que os resultados do presente estudo apontem para o retorno em função da não adaptação, já que a saudade da família foi um dos fatores determinantes para o retorno

Por fim, os resultados do presente estudo demonstraram que o retorno dos atletas foi algo muito informal e sem um planejamento prévio, corroborando a literatura ${ }^{3,7,9,17,36}$. A literatura aponta que os clubes encaram com naturalidade a possibilidade de os atletas não se adaptarem e retornarem ao Brasil ${ }^{3}$. Sendo assim, a literatura, além dos resultados do presente estudo, sugerem que o atleta precisa, por conta própria, buscar o autodesenvolvimento sobre sua adaptação, bem como sobre seu sucesso no exterior e sobre seu retorno ${ }^{7,17}$. Assim, os resultados do presente estudo, bem como da literatura, sugerem que os atletas não são preparados para a expatriação, tão pouco para o retorno $3,7,9,16,17,36,49$.

Corroborando as propostas já discutidas de adaptação do expatriado ${ }^{35,39}$, SousA ${ }^{36}$ sugere que as novas tecnologias podem contribuir com o expatriado e com sua família. Isso pode ser explicado pelo fato de que as novas tecnologias reduzem, em termos, a saudade e o sentimento de perda das relaçóes sociais que o expatriado mantinha no país de origem. Essas informações vão de encontro com a literatura, demonstrando que as novas tecnologias dão suporte ao expatriado, para que o mesmo suporte com maior facilidade a distância de seu país de origem ${ }^{50-52}$.

Considerando os objetivos do presente estudo, os dados demonstram que o retorno dos atletas foi motivado pela saudade da família e despreparado das equipes em adaptar o atleta ao novo clube, corroborando a literatura ${ }^{3,7,9,17,36}$. Essas informaçóes foram suportadas com os resultados que apresentaram a saudade da família e o término de contrato como os motivos que mais motivaram o retorno do expatriado para o Brasil. Entretanto os resultados demonstram que o retorno dos atletas ocorreu de forma amadora, sem planejamento ou intenção, corroborando com a literatura ${ }^{3,7,9,17,36}$.

Assim, os resultados sugerem que deve-se elaborar treinamento para o processo de expatriação, respeitando as individualidades do Voleibol, assim como de outras modalidades esportivas. Para isso, os programas devem assumir questóes de ajustamento intercultural como fundamentais no treinamento. Enquanto treinamento intercultural, de acordo com os resultados do presente estudo e de outros estudos $^{3,7,9,15,17}$, o papel da família no processo de adaptação e no sucesso da expatriação é essencial.

Finalizando, deve-se estabelecer modelos em que a família esteja envolvida, tanto no treinamento, quanto na expatriação propriamente dita. Isso é relevante para o processo de expatriação, pois SousA $^{36}$ e outros autores demonstraram, em seus estudos, que a família próxima do expatriado pode contribuir para seu processo de adaptação $33,35,46,53,54$. Assim, espera-se que novos estudos sejam conduzidos, avaliando os benefícios que o treinamento intercultural pode levar ao processo de expatriação do atleta de Voleibol, assim como de outras modalidades esportivas. 


\section{Abstract \\ Grounds that take the Volleyball players to return to Brazil after expatriation}

The objective of the present study was to analyze the reasons that lead Volleyball athletes to return to their country of origin after the expatriation and how they evaluate the process of expatriation for their career. Participated 30 people, 20 athletes ( 17 men and 3 women), and 10 ex-athletes ( 2 men and 8 women), with an average age of 30.96 years. The instrument used was developed and validated via TRI, using the adjustment to the Rasch model. It was constructed in 2 parts, the first part responsible for general characteristics, containing open and closed questions, and the second part responsible for adaptation issues, containing only closed questions with 5-point Likert-type responses. In the present study, only the issues pertinent to the objectives were analyzed. For inferential analyzes, one-way ANOVA was used with repeated measures in the last factor, paired t-test and Pearson's correlation. When significant differences were found, post hoc tests were conducted. The results showed that the athletes presented as the motive that caused the most return to Brazil, the homesickness of the family $(p=0.014)$. Nonetheless, athletes considered the expatriation profitable, probably because they understood the value of cultural and professional enrichment that the process brought, even though they did not earn the expected salaries and wages. Based on these findings, it can be concluded that the most important reason for the return of the athlete to Brazil was the family, demonstrating the need for intercultural training with the athlete, and the search for models of expatriation involving the family in the process, with the aim to minimize the damages caused by longing for family.

KEYwORDS: Sports Psychology; Expatriation; Volleyball; Motivation.

\section{Referências}

1. Proni MW. Esporte-espetáculo e futebol-empresa [tese]. Campinas (SP): Universidade Estadual de Campinas; 1998.

2. Andreff W. Globalization of the sports economy. Riv Dirit Econ dello Sport. 2008;4(3):13-32.

3. Machado FS. Gestão de pessoas interncional no contexto esportivo brasileiro: uma análise dos processos de expatriaçấo e repatriaçáo de jogadores em um clube de futebol gaúcho [dissertação]. Porto Alegre (RS): Universidade Federal do Rio Grande do Sul, Escola de Administração; 2013.

4. Andreff W. Why tax international athlete migration? The 'coubertobin' tax in a context of financial crisis. In: Maguire J, Falcous M, editors. Handbook on Sport and Migration: borders, boundaries and crossings. Oxon: Routledge; 2010. p. 31-45.

5. Tertuliano IW. Processo de expatriação de voleibolistas: concepçōes bioecológicas [tese]. Rio Claro (SP): Universidade Estadual Paulista Júlio de Mesquita Filho; 2016.

6. Brandão JPP. Processos de expatriaçấo na Gestão Internacional de Recursos Humanos (GIRH): fatores que influenciam a performance dos expatriados [dissertação]. Porto (PO): Universidade do Porto; 2012.

7. Brandão MRF, Magnani A, Tega E, Medina JP. Além da cultura nacional : o expatriado no futebol. Rev Bras Ci e Mov; 2013;21(2):177-82.

8. Teixeira F. Expatriados Futebol Clube. Belo Horizonte: Editora do autor; 2014.

9. Rial C. Rodar: a circulaçẫo dos jogadores de futebol brasileiros no exterior. Horiz Antropol. 2008;14(30):21-65.

10. Bizzocchi CC. O voleibol de alto nível: da iniciação à competiçáo. Barueri: Manole; 2008.

11. Confederação Brasileira de Voleibol [Internet]. 2015 [citado 17 maio 2015]. Disponível em: http://www.cbv.com.br

12. Confederação Brasileira de Futebol [Internet]. 2015 [citado 17 maio 2015]. Disponível em: http://www.cbf.com.br

13. Bianchi EMPG. Gestão e carreira internacional: repatriação - construindo elos entre ciclos. In: 35o Encontro da Anpad; 4-7 set 2011; Rio de Janeiro, BR. Rio de Janeiro: Anpad; 2011.

14. Tanure B, Evans P, Pucik V. Virtudes e pecados capitais: a gestão de pessoas no Brasil. Rio de Janeiro: Elsevier; 2007.

15. Rodrigues FXF. O fim do passe e as transferências de jogadores brasileiros em uma época de globalizaçấo. Sociologias. 2010;12(24):338-80.

16. Sebben A. Andrea Sebben, psicóloga (Parte 1). Mesquita Online [Internet]. 2009 [citado 17 maio 2015]. Disponível em: http://universidadedofutebol.com.br/andrea-sebben-psicologa-parte-1/. 
17. Freitas LPR, Costa Neto JR, Cardoso RM, Ferreira MPP. Estudo do fenômeno do regresso de ex-atletas sul-mineiros de futebol do exterior. EFDeportes.com [Internet]. 2012 [citado 26 jul 2019];16(164). Disponível em: https://www.efdeportes. com/efd164/regresso-de-sul-mineiros-de-futebol-do-exterior.htm.

18. Pisani MS. Migraçóes e deslocamentos de jogadoras de futebol : mercadoria que ninguém compra? Esporte Soc. 2014;9(23):1-11.

19. Machado AA. Voleibol se aprende na escola. Várzea Paulista: Fontoura; 2014.

20. Fontes RCC, Brandão MRF. A resiliência no âmbito esportivo: uma perspectiva bioecológica do desenvolvimento humano. Motriz. 2013;19(1):151-9.

21. 21. Carvalho LF, Ambiel RAM. Aplicação do modelo de resposta graduada em testes psicologicos. In: Silva MCR, Bartholomeu D, Vendramini CMM, Montiel JM, editores. Aplicaçóes de métodos estatísticos avançados à avaliação psicológica e educacional: com ilustraçôes em diferentes softwares estatísticos. São Paulo: Vetor; 2015. p. 91-104.

22. Kozinets RV. Netnografia: realizando pesquisa etnográfica online. Porto Alegre: Penso; 2014.

23. Pagano M, Gauvreau K. Princípios de Bioestatística. 2a ed. São Paulo: Pioneira Thomson Learning; 2004.

24. Thomas JR, Nelson JK, Silverman SJ. Métodos de Pesquisa em Atividade Física. Ga ed. Porto Alegre: Artmed; 2012.

25. Guedes TA, Martins ABT, Acorsi CRL, Janeiro V. Estatística descritiva. In: Guedes TA, Martins ABT, Acorsi CRL, Janeiro V, editores. Projeto de ensino aprender fazendo estatística. Maringá: Universidade Estadual de Maringá; 2005. p. 1-49.

26. Field A. Descobrindo a estatística usando o SPSS. São Paulo: Bookman; 2009.

27. Bartholomeu D, Montiel JM, Machado AA. Avaliação da escala likert dos itens do CSAI-2 em atletas. Interação Psicol. 2013;17(1):79-89.

28. Green SB, Salkind NJ, Akey TM. Using SPSS for windows: analyzing and understanding data. 2nd ed. New Jersey: Prentice Hall; 2000.

29. Black JS, Mendenhall M. Cross-cultural training effectiveness: a review and theoretical framework for future research. Acad Manag Rev. 1990;15(1):113-36.

30. Black JS. Work role transitions: a study of American expatriate managers in Japan. J Int Bus Stud. 1988;19(2):277-94.

31. Araujo BFVB, Teixeira MLM, Cruz PB, Malini E. Adaptação de expatriados organizacionais e voluntários: similaridades e diferenças no contexto brasileiro. Rev Adm São Paulo. 2012;47(4):555-70.

32. Holopainen J, Björkman I. The personal characteristics of the successful expatriate. Pers Rev Bingley. 2005;34(1):37-50.

33. Machado HV, Hernandes CA. Alteridade, expatriação e trabalho: implicaçôes para a gestão organizacional. Rev Adm Contemp. 2004;8(3):53-73.

34. Black JS, Gregersen HB. The right way to manage expats. Harv Bus Rev. 1999;77:52-63.

35. Pereira NAF, Pimentel R, Kato HT. Expatriaçáo e estratégia internacional: o papel da família como fator de equilíbrio na adaptação do expatriado. Rev Adm Contemp. 2005;9(4):53-71.

36. Sousa AFB. A adaptação intercultural da família: um estudo exploratório com expatriados portugueses [dissertação]. Vila do Conde (PO): Instituto Politécnico do Porto; 2014.

37. Dowling PJ, Festing M, Engle AD. International human resource management: managing people in a multinational context. 5th ed. São Paulo: Cengage Learning; 2008.

38. Cieri HD, Dowling PJ, Taylor KF. The psychological impact of expatriate relocation on partners. Int J Hum Resour Manag. 1991;2(3):377-414.

39. Shaffer MA, Ferzandi LA, Harrison DA, Gregersen H, Black JS. You can take it with you: individual differences and expatriate effectiveness. J Appl Psychol. 2006;91(1):1-35.

40. Rubio K. Jogos olímpicos da era moderna: uma proposta de periodização. Rev Bras Educ Fís Esporte. 2010;24(1):55-68.

41. Rubio K. Rendimento esportivo ou rendimento humano? o que busca a da Psicologia do esporte? Psicol Am Lat [Internet]. 2004 [citado 26 jul 2019];(1). Disponível em: http://pepsic.bvsalud.org/scielo.php?script=sci_abstract\&pid=S1870-350X2 $004000100004 \& \operatorname{lng}=$ en\&nrm=iso.

42. Lavoura TN, Schwartz GM, Machado AA. Aspectos emocionais da prática de atividades de aventura na natureza: a (re) educação dos sentidos. Rev Bras Educ Fís Esporte. 2008;22(2):119-27.

43. Moraes LC, Oliveira DC. Emoçóes em situaçôes de risco no alpinismo de alto nível. Rev Bras Psicol Esporte Exerc. São Paulo; 2006;0:4-21.

44. Lavoura TN, Machado AA. Esporte de aventura de rendimento e estados emocionais: relaçóes entre ansiedade, autoconfiança e auto-eficácia. Motriz. 2006;12(2):143-8.

45. Lavoura TN, Zanetti MC, Machado AA. Os estados emocionais e a importância do treinamento psicológico no esporte. Motriz. 2008;14(2):115-23. 
Tertuliano IW, et al.

46. Carvalho SMS. A relação entre a gestão da carreira e a expatriação: um estudo quantitativo com repatraidos portugueses [dissertação]. Vila do Conde (PO): Instituto Politécnico do Porto; 2016.

47. Bastid F, Bravo B. Ter sucesso na carreira: abordagem conceptual. In: Akremi AEL, Sylvie G, Neveu JP, editores. Comportamento organizacional: justiça organizacional, expectativas de carreira e esgotamento profissional. 2a ed. Lisboa: Instituto Piaget; 2013. p. 173-202.

48. Kanter RM. Careers and the wealth of nations: a macro-perspective on the structure and implications of career forms. In: Arthur MB, Hall DT, Lawrence BS, editors. Handbook of career theory. Cambridge: Cambridge University Press; 1989. p. 506-21.

49. Lanfranchi P, Taylor M. Moving with the ball: the migration of the professional footballers. Oxford: Bloomsbury Academic; 2001.

50. Copeland AP, Norell SK. Spousal adjustment on international assignments: the role of social support. Int J Intercult Relations. 2002;26(3):255-72.

51. Herleman HA, Britt TW, Hashima PY. Ibasho and the adjustment, satisfaction, and well-being of expatriate spouses. Int J Intercult Relations. London; 2008;32(3):282-99.

52. Lin CYY, Lu TC, Lin HW. A different perspective of expatriate management. Hum Resour Manag Rev. 2012;22(3):189-207.

53. Tung RL. American expatriates abroad: from neophytes to cosmopolitans. J World Bus. 1998;33(2):125-44.

54. Stahl GK, Miller EL, Tung RL. Toward a boundaryless career: a closer look at the expatriate career concept and the perceived implications of an international assignment. J World Bus. 2002;37:216-27.

ENDEREÇO

Ivan Wallan Tertuliano

Rua Apucarana, 220 - apto 91 - 03311-ooo

Tatuapé - São Paulo - SP - BRASIL e-mail: ivanwallan@gmail.com
Recebido para publicação: 21/09/2017

Revisado: 09/02/2018

Aceito: 07/03/2018 